\title{
Pengaruh Destination Image dan Tourist Atraction terhadap Tourist Satisfaction dan Post Visit Behavioral Intention
}

\author{
Anisa Destiana ${ }^{1}$, Eny Endah Pujiastuti ${ }^{2}$, Sadeli $^{3}$ \\ eny_endah@yahoo.co.id
}

\begin{abstract}
The purpose of this study is to understand the influence between Destination Image, Tourist Atraction, Tourist Satisfaction and Post Visit Behavioral Intention. In this study, a total of 115 effective questionnaires were collected which would then be processed using Structural Equating Modeling (SEM) which was operated using the AMOS application. The results of the study show that 1). Destination image has a significant effect on tourist satisfaction. 2). Tourist attraction has a significant effect on tourist satisfaction. 3). Destination image has a significant effect on the post visit behavior intention. 4). Tourist attraction has a significant effect on the post visit behavior intention. 5). Tourist satisfaction has a significant effect on the post visit behavior intention. 6). Destination image has an indirect effect on post visit intention behavior through tourist satisfaction. 7). Tourist attraction influences indirectly on post visit intention behavior through tourist satisfaction. Based on the results of the research, the research not only provides advice for the government tourism sector, but also provides direction for future research.
\end{abstract}

Keyword: revisit intention, Tourist attraction, Brand, Motivation

\begin{abstract}
Abstrak
Tujuan dari penelitian ini adalah untuk memahami pengaruh antara Citra Destinasi, Daya Tarik Wisata, Kepuasan Wisatawan dan Intensi Perilaku Pasca Kunjungan. Dalam penelitian ini, total 115 kuesioner efektif dikumpulkan yang kemudian akan diproses menggunakan Structural Equating Modeling (SEM) yang dioperasikan menggunakan aplikasi AMOS. Hasil penelitian menunjukkan bahwa 1). Citra destinasi berpengaruh signifikan terhadap kepuasan wisatawan. 2). Daya tarik wisata berpengaruh signifikan terhadap kepuasan wisatawan. 3). Citra tujuan berpengaruh signifikan terhadap niat perilaku pasca kunjungan. 4). Daya tarik wisata berpengaruh signifikan terhadap niat perilaku pasca kunjungan. 5). Kepuasan wisatawan memiliki pengaruh yang signifikan terhadap niat perilaku pasca kunjungan. 6). Citra destinasi memiliki efek tidak langsung pada perilaku niat pasca kunjungan melalui kepuasan pasca wisatawan. 7). Daya tarik wisata mempengaruhi secara tidak langsung perilaku niat kunjungan melalui kepuasan wisatawan. Berdasarkan hasil penelitian, penelitian ini tidak hanya memberikan saran untuk sektor pariwisata pemerintah, tetapi juga memberikan arahan untuk penelitian masa depan.
\end{abstract}

Kata Kunci: Niat Kunjungan Kembali, Objek Wisata, Merek, Motivasi

1,2,3 UPN "Veteran" Yogyakarta 


\section{Pendahuluan}

Saat ini merupakan era milenial dimana era milenial ini dapat mempengaruhi perubahan perilaku wisatawan. Perilaku wisatawan yang usianya termasuk milenial seperti wisatawan suka berkunjung di tempat tempat yang bagus dan memiliki spot foto. Hal ini dikarenakan wisatawan menyukai selfi untuk eksis diri dengan menampilkan foto tersebut dalam status media sosial. Trend tersebut sangat menguntungkan pengelola destinasi wisata. Perubahan perilaku wisatawan tersebut harus diperhatikan oleh pengelola destinasi wisata. Pengelola tempat wisata wajib memikirkan apa saja yang dapat menarik perhatian kaum milenial, agar destinasi wisata tersebut banyak yang dikunjungi oleh wisatawan. Pengelola wisata meningkatkan kemampuan inovasi dan kreativitasnya agar wisatawan melakukan kunjungan berulang atau revisit.

Behavior intention adalah perilaku yang selalu mengacu pada perilaku masa depan dan sering dikaitkan dengan perilaku keseluruhan (Fishbein dan Ajzen, 1975). Perilaku wisatawan dimasa yang akan datang (behavior intention) merupakan bentuk keinginan untuk pembelian ulang terhadap kunjungan destinasi. Niat berperilaku dipengaruhi oleh beberapa faktor yaitu kepuasan (Pujiastuti, Nimran, Suharyono dan Kusumawati, 2017 dan Manhas dan Ramjit (2013), destination image (Moon et al, 2013 dan Pujiastuti et al., 2017) dan tourist attraction (Hsieh, 2012).

Kepuasan (satisfaction) menurut Barnest (2003) adalah tanggapan pelanggan atas terpenuhinya kebutuhannya. Kepuasan pelanggan dalam konteks pariwisata juga didefinisikan sebagai keadaan mental yang positif dari wisatawan tentang pengalaman yang diperoleh saat bepergian (Meng dan Uysal 2008). Hasil penelitian yang dilakukan oleh Tang (2014) diketahui bahwa kepuasan dipengaruhi oleh tourist attraction dan destination image serta hasil penelitian dari Naidoo et al., (2011). Hasil penelitian lain yang menunjukkan bahwa kepuasan dipengaruhi oleh destination adalah penelitian yang dilakukan oleh Pujiastuti et al., (2017), Manhas dan Ramjit (2013), Tang (2014), Khan et al., (2013), dan Naidoo et al., (2011).

Tourist attraction menurut Ismayanti (2010) adalah merupakan fokus utama penggerak pariwisata di sebuah destinasi. Daya tarik wisata dapat dipergunakan untuk memotivasi wisatawan untuk datang ke suatu objek wisata. Motivasi dapat berasal dari internal atau emosional karakteristik wisatawan maupun dari eksternal dan faktor situasional seperti pengetahuan turis atau citra destinasi tertentu (Crompton dan McKay 1997, Dann, Nash, dan Pearce, 1988; Gnoth, 1997; Uysal dan Jurowski, 1994 dalam Tang 2014).

Faktor lainnya yang mempengaruhi kepuasan dan niat kunjung kembali wisatawan adalah destination image. Image menurut Barnest (2003) adalah sebuah pengalaman aktif, menciptakan nilai yang sangat besar bagi pelanggan. Penetapan merek menciptakan presepsi yang membantu konsumen mengatur pengetahuan mereka tentang produk dan jasa yang diberikan. Citra merek adalah penggerak utama ekuitas merek, yang mengacu pada persepsi umum tentang konsumen dan perasaan tentang merek, dan mempengaruhi konsumen perilaku (Zhang 2015). Berdasarkan kajian penelitian terdahulu tersebut, maka penelitian ini mengkaji mengenai 
destination image, tourist attraction, satisfaction dan behavior intention.

Penelitian ini memilih objek wisata Kebun Buah Mangunan, karena merupakan inovasi baru didunia pariwisata, yaitu berdasarkan inisiatif Pemerintah Kabupaten Bantul untuk mencoba mengubah lahan marginal menjadi lahan produktif. Kebuh Buah ini dibangun di kawasan perbukitan di sisi timur Kabupaten Bantul oleh Pemerintah daerah setempat, berdiri diatas lahan seluas 23,3415 hektar pada ketinggian 150-200 meter di atas permukaan laut. Kebun Buah Mangunan memiliki pesona keindahan alamnya dengan potensi pengembangan tempat wisata yang cukup besar. Adanya daya tarik pada objek wisata membuat wisatawan ingin berkunjung, rata-rata pada hari biasa ada 100 pengunjung dan 500 pengunjung pada hari libur sejak Januari 2016

(Sumber:http://www.pikiran-

rakyat.com/wisata/2016/01/08/356276/ kebun-buah-mangunan-kian-terkenal,8 Januari 2016. Diakses pada tanggal 11 September 2018, pukul 19:10 WIB).

Kebun Buah Mangunan merupakan objek penelitian yang sesuai karena berdasarkan google review diketahui adanya ketidakpuasan dari wisatawan terhadap Kebun Buah Mangunan. Adapun ketidakpuasan wisatawan sebagai berikut :1) Akses jalan menuju lokasi masih kurang baik (Arin 18 tahun). 2) Sarana prasarana yang kurang memadahi (Raa 24 tahun).

3) Objek wisata tidak sesuai dengan ikon nama tempatnya (Juliawati 28 tahun).

(Sumber:https:www.tripadvisor.co.id/A ttraction_Review-g294230

d8062041Reviewsor40-

Fruit_Garden_Mangunan_YogyakartaYogyakarta_Java.html (Diakses pada tanggal 11 September 2018, pukul 19:08).

Permasalahan lain juga diketahui berdasarkan observasi peneliti di lapangan dengan cara mewawancarai beberapa wisatawan. Berikut adalah beberapa ulasan wisatawan yang sedang berkunjung di objek wisata Kebun Buah Mangunan (1 Desember 2018, pukul 15:15-17:20 WIB): 1). Spot foto yang kurang banyak, 2). Toilet yang terbatas, 3). Spot foto kurang menarik dan membosankan dan 4). Nama tempat tidak sesuai dengan realita di lapangan.

\section{Kajian Pustaka}

\section{Destination Image}

Image menurut Barnest (2003:315) adalah sebuah pengalaman aktif, menciptakan nilai yang sangat besar bagi pelanggan. Penetapan image merek (branding) menurut Kotler dan Keller (2009:260) adalah memberikan kekuatan merek kepada produk dan jasa. Penetapan merek menciptakan persepsi yang membantu konsumen mengatur pengetahuan mereka tentang produk dan jasa yang diberikan. Destination image menurut Santos (1994) dalam Utama (2017:221) adalah sebuah representasi mental seseorang tentang beberapa atribut dan keuntungan yang didapat pada sebuah produk. Sedangkan, pengertian destination image menurut Parenteau (1995) dalam Utama (2017:221) adalah prasangka positif atau negatif yang dimiliki oleh seorang pelanggan tentang sebuah produk atau destinasi.

Citra destinasi menurut Beerli dan Martin (2004) dalam Utama (2017: 224) diklasifikasikan menjadi 9 atribut yaitu :

1. Natural Resumbers

Dimanifestasikan dalam bentuk: iklim (suhu dan kelembaban udara), 
pantai (pasir, air laut, ombak), dan alam pedesaan ( flora, fauna, taman, danau, dan gunung).

2. Natural Environment

Dimanifestasikan dalam bentuk: pemandangan alam, daya tarik, kebersihan, polusi, kemacetan dan kebisingan.

3. Culture, History, and Art

Dimanifestasikan dalam bentuk: festival, kerajinan, agama, adat istiadat, dan bangunan bersejarah.

4. Tourist Infrastructure

Dimanifestasikan dalam bentuk: hotel, restoran, pusat hiburan dan rekreasi.

5. Atmosphere of Te Place

Dimanifestasikan dalam bentuk: kenyamanan, kesejukan, kehangatan reputasi destinasi.

6. Tourist Leasure and Recreation Dimanifestasikan dalam bentuk: kesempatan melakukan aktivitas wisata seperti memancing, berburu, surfing, diving, trekking hiburan malam dan sebagainya.

7. General Infrastructure

Dimanifestasikan dalam bentuk: jalan raya, bandara, transportasi umum, rumah sakit, drainase, dan fasilitas komunikasi.

8. Social Environtment

Dimanifestasikan dalam bentuk: kualias hidup, kemiskinan, bahasa, dan keramahan penduduk.

9. Political and Economic Factors

Dimanifestasikan dalam bentuk: stabilitas politik, keamanan, terorisme, dan harga.

\section{Tourist Atraction}

Daya tarik wisata menurut Pandit (2003) dalam Utama (2017:142) adalah segala sesuatu yang menarik dan mempunyai nilai untuk dikunjungi dan dilihat. Daya tarik wisata menurut Undang- Undang Republik Indonesia
Nomor 10 Tahun 2009 adalah segala sesuatu yang mempnyai keunikan, kemudahan, dan nilai yang berwujud keanekaragaman, kekayaan alam, budaya dan hasil buatan manusia yang menjadi sasaran atau kunjungan para wisatawan. Daya tarik wisata menurut Yoeti (1997) dalam Suwena dan Widyatmaja (2017:155) menyatakan bahwa daya tarik wisata atau tourism attraction ialah segala sesuatu yang menjadi daya tarik bagi orang untuk mengunjungi daerah wisata tertentu mempunyai kekhususan dan berbeda dari objek yang lain.

Daya tarik wisata dapat menjadi penentu wisatawan untuk berkunjung. Berikut merupakan faktor- faktor daya tarik wisata menurut Aryanto (2005) dalam Utama (2017: 143) yaitu terdapat 5 faktor yang menjadikan suatu daerah memiliki daya tarik untuk dikunjungi:

1. Lokasi

Lokasi merupakan suatu yang penting untuk menjamin keterjangkauan wisatawan. Mudahnya lokasi tempat wisata dapat dengan mudah dijangkau maka akan menjadi nilai tambah dalam benak wisatawan.

2. Fasilitas

Fasilitas yang merupakan penunjang yang sangat diperlukan untuk tempat wisata. Adanya fasilitas yang baik dapat memenuhi espektasi wisatawan tentang tempat wisata.

3. Citra atau Image

Citra suatu tempat wisata merupakan faktor pendorong yang dapat mempengaruhi wisatawan dalam berkunjung, karena dapat membangun ketertarikan dengan citra yang ditanamkan.

4. Harga atau tarif

Harga tidak hanya menentukan profitabilitas tapi juga sebagai alat yang ampuh bagi pemasar untuk 
mencapai tujuan strategis bisnis dan alat taktis. Wisatawan yang dapat memutuskan apakah suatu produk harus dihargai berapa dan bagi pemasar sangat penting penetapan harga sesuai dengan nilai yang dibayangkan oleh wisatawan.

5. Pelayanan

Pelayanan yang diberikan berdampak pada persepsi wisatawan. Wisatawan pada umumnya mendambakan pelayanan yang ramah, terorganisir teratur, dan cepat.

\section{Tourist Satisfaction}

Westbrook (1980) "refers to the favorability of the individual's subjective evaluation of the various outcomes and experiences associated with using or consuming it". Westbrook and Oliver (1991) "evaluative evaluation of the choice of posts regarding certain purchases choices ".Severt et al. (2007) define tourist satisfaction as the extent of the tourist's fulfillment pleasure which occured from the trip experience about a product or service feature that fulfills the tourist's desires. Satisfaction is defined as customers' judgments about products or service fulfilment (Oliver, 1993 dan Oliver, 1997).

\section{Behavioral Intention}

Niat pembelian ulang menurut Kotler (2009: 190) pada dasarnya adalah perilaku pelanggan yang merespons positif terhadap kualitas pelayanan suatu perusahaan bila memenuhi harapan konsumen atau bahkan melebihi harapan pelanggan maka pelanggan akan berniat melakukan kunjungan kembali atau mengkonsumsi kembali produk perusahaan tersebut bahkan pelanggan akan menyampaikan hal-hal yang baik kepada orang lain. Niat kunjung ulang menurut Mowen dan Minor (2002:322) adalah keinginan konsumen untuk berperilaku menurut cara tertentu dalam rangka memiliki, membuang dan menggunakan produk atau jasa.

Faktor pendorong dan faktor penarik tersebut menurut Khan, dkk (1993) dalam Utami (2017:114) :

a. Faktor Pendorong (Press Factors)

1. Psycological factor terdiri dari :
a) Motivations (psychological): motivasi psikologis
b) Escape : ingin menyendiri
c) Rest and Relaxation: istirahat dan relaksasi
d) Prestige: martabat atau gengsi
e) Health and fitness: kesehatan dan kebugaran
f) Adventure : petualangan
g) Social interaction: interaksi sosial
h) Benefits: mencari manfaat
i) Interest: minat khusus
j) Self-esteem: harga diri

2. Socioeconomic and demographic factors, terdiri dari:
a. Age: Umur
b. Gender
c. Income: pendapatan
d. Education: pembelajaran
e. Family life-cycle and size: gaya hidup keluarga
f. Racelethnic group: kelompok ras/ etnik
g. Occupation : pekerjaan
h. Second home ownership

3. Market Knowledge: Pengetahuan tentang pariwisata

a. Faktor Penarik (Pull Factors)

3. Destination Attribute and Type of Facilities (knowledge):
a. Climate: iklim
b. Histori sights: situs sejarah
c. Scenic Beauty: keindahan alam
d. Sunshine : sinar matahari
e. Beaches: pantai 
f. Snow: salju

g. Cultural events: pergelaran budaya

h. Recreational opportunities: kesempatan berekreasi

i. Benefit Expectations: berharap manfaat

4. Accebility and Marketed Image (Preceptions and Expectations) terdiri dari :

a. Formed negative or positive destination image: Citra terhadap destinasi

b. Quality of service: Kualitas pelayanan

c. Quality of facilities: Kualitas fasilitas

\section{Hipotesis}

Adapun hipotesis yang disusun dalam penelitian ini sebagai berikut:

\section{a. Pengaruh Destination Image terhadap Tourist Satisfaction}

Destination image merupakan prasangka positif atau negatif yang dimiliki oleh seorang tentang sebuah produk atau destinasi. Persepsi tersebut muncul berdasarkan kesan yang didapat oleh wisatawan saat berkunjung (Parenteau (1995) dalam Utama 2017:221). Salah satu faktor pembentuk kepuasan wisatawan menurut Irawan (2002:37) adalah emotional factor, yaitu wisatawan merasa yakin dengan objek wisata yang mereka kunjungi, persepsi yang baik akan muncul jika realita dan ekspeksasi tentang objek wisata dinilai sesuai oleh wisatawan. Prasangka positif tersebut akan berdampak pada kepuasan wisatawan saat berkunjung. Pendapat diatas dipertegas dengan penelitian yang dilakukan oleh Pujiastuti et al., (2017), Manhas dan Ramjit (2013), Tang (2014), Khan et al., (2013), dan Naidoo et al., (2011) membuktikan bahwa destination image memiliki pengaruh positif terhadap tourist satisfaction. Berdasarkan uraian diatas menjadi sarana acuan peneliti untuk mengembangkan hipotesis sebagai berikut:

$H_{l}$ : Destination image berpengaruh signifikan terhadap tourist satisfaction.

\section{b. Pengaruh Tourist Attraction terhadap Tourist Satisfaction}

Daya tarik wisata adalah segala sesuatu yang menarik dan mempunyai nilai untuk dikunjungi dan dilihat. Daya tarik wisata merupakan salah satu pemicu kepuasan wisatawan dan juga merupakan pendorong agar wisatawan rela berkunjung ke suatu objek wisata (Pandit (2003) dalam Utama 2017:142). Beberapa faktor kepuasan wisatawan menurut Irawan (2002:37) adalah kualitas produk, service quality, dan kemudahan. Wisatawan merasa puas bila hasil evaluasi menunjukan bahwa objek wisata yang dikunjungi mempunyai fasilitas yang baik, seperti fasilitas umum yang ada. Wisatawan akan merasa puas apabila mereka mendapatkan pelayanan yang baik dari pengelola objek wisata atau dalam arti lain yaitu sesuai dengan harapkan wisatawan. Wisatawan merasa puas karena lokasi objek wisata yang mudah dijangkau. Maka dari itu, daya tarik wisata merupakan hal yang penting dalam kepuasan wisatawan, sebab daya tarik merupakan pembeda dan menjadi suatu yang dapat ditawarkan untuk memenuhi keinginan. Pendapat diatas dipertegas dengan penelitian yang dilakukan oleh Naidoo et al., (2011), dan juga Manhas dan Ramjit (2013) membuktikan bahwa tourist attraction memiliki pengaruh positif terhadap tourist satisfaction. Berdasarkan uraian diatas menjadi sarana acuan peneliti untuk mengembangkan hipotesis sebagai berikut: 


\section{$\mathrm{H}_{2}$ : $\quad$ Tourist attraction berpengaruh signifikan terhadap tourist satisfaction.}

\section{c. Pengaruh Destination Image terhadap Post Visit Behavior Intention}

Pengalaman aktif, menciptakan nilai yang sangat besar merupakan komponen dari terbentuknya citra destinasi. Destination image menjadi kompleks karena masih banyaknya perdebatan terhadap cara pengukurannya, dan banyaknya komponen yang disertakan dalam pengukuran (Barnest 2003:315). Faktor pendorong wisatawan untuk melakukan post visit behavior intention menurut Khan, dkk (1993) dalam Utama (2017:114) adalah psycological factor dan preceptions and expectations. Image objek wisata timbul relatifitasnya disebabkan oleh cara penafsirannya yang subjektif antara seorang dengan yang lainnya dan sangat tergantung dengan perbandingan yang akan digunakan. Citra destinasi adalah penggerak utama yang mengacu pada persepsi umum wisatawan, dan dapat mempengaruhi perilaku dimasa yang akan datang. Semakin tinggi pengaruh presepsi positif yang diberikan, maka semakin besar juga kemungkinan wisatawan untuk melakukan niat kunjung ulang. Pendapat diatas dipertegas dengan penelitian yang dilakukan oleh Moon et al., (2013), Pujiastuti et al., (2017), Tang (2013), Hsieh (2012), membuktikan bahwa destination image memiliki pengaruh positif terhadap behavior intention. Berdasarkan uraian diatas menjadi sarana acuan peneliti untuk mengembangkan hipotesis sebagai berikut:

$$
\begin{aligned}
& \mathrm{H}_{3}: \text { Destination image } \\
& \text { berpengaruh signifikan terhadap } \\
& \text { post visit behaviour intention. }
\end{aligned}
$$

\section{d. Pengaruh Tourist Attraction terhadap Post Visit Behavior Intention}

Daya tarik wisata segala sesuatu yang menjadi daya tarik bagi orang untuk mengunjungi daerah wisata tertentu mempunyai kekhususan dan berbeda dari objek yang lain (Yoeti (1997) dalam Suwena dan Widyatmaja 2017:155). Salah satu faktor pendorong post visit behavior intention menurut Khan, dkk (1993) dalam Utama (2017:114) adalah destination attribute and type facilities. Daya tarik wisata berupa keindahan alam (scenic beauty) sangat penting untuk mempengaruhi wisatawan agar dapat berkunjung, sebab adanya daya tarik wisata itu dapat menjadi pembeda suatu tempat wisata dengan tempat wisata lainnya. Perbedaan itu yang dapat menjadi peluang besar tempat wisata untuk menarik wisatawan berkunjung. Daya tarik alam objek wisata jika semakin dikembangkan dengan beberapa inovasi-inovasi baru maka dapat berpengaruh pada presepsi konsumen untuk mengunjungi objek wisata dengan kedatangannya yang lebih dari satu kali. Pendapat diatas dipertegas dengan penelitian yang dilakukan oleh Hsieh (2012) membuktikan bahwa tourist attraction berpengaruh positif terhadap post visit behaviour intention. Berdasarkan uraian diatas menjadi sarana acuan peneliti untuk mengembangkan hipotesis sebagai berikut:

$\mathrm{H}_{4} \quad$ : Tourist attraction berpengaruh signifikan terhadap post visit behavior intention.

\section{e. Pengaruh Tourist Satisfaction terhadap Post Visit Behavior Intention}

Kepuasan wisatawan adalah perbandingan antara apa yang diharapkan dengan tingkat kinerja yang 
dirasakan oleh wisatawan (Suwena dan Widyatmaja (2017:75). Kepuasan merupakan hal positif dalam sebuah psikologis seseorang, karena dengan adanya kepuasan berarti bahwa produsen atau pengelola sudah dapat memenuhi kebutuhan, keinginan dan harapan konsumen atas suatu produk atau jasa, sehingga berdampak pada perilaku konsumen terhadap perilaku berikutnya. Pendapat diatas dipertegas dengan penelitian yang dilakukan oleh oleh Manhas dan Ramjit (2013) membuktikan bahwa tourist satisfaction berpengaruh positif terhadap post visit behavior intention. Berdasarkan uraian diatas menjadi sarana acuan peneliti untuk mengembangkan hipotesis sebagai berikut:

$\mathrm{H}_{5}$ : Tourist satisfaction berpengaruh signifikan terhadap post visit behavior intention.

\section{f. Pengaruh Destination Image terhadap Post Visit Behavior Intention melalui Tourist Satisfaction}

Kepuasan wisatawan adalah perbandingan antara apa yang diharapkan dengan tingkat kinerja yang dirasakan oleh wisatawan (Suwena dan Widyatmaja (2017:75). Salah satu faktor pembentuk kepuasan wisatawan menurut Irawan (2002:37) adalah emotional factors, yaitu wisatawan merasa yakin dengan objek wisata yang mereka kunjungi, persepsi yang baik akan muncul jika realita dan ekspeksasi tentang objek wisata dinilai sesuai oleh wisatawan. Prasangka positif tersebut akan berdampak pada kepuasan wisatawan saat berkunjung. Faktor pendorong wisatawan untuk melakukan post visit behavior intention menurut Khan, dkk (1993) dalam Utama (2017:114) adalah psycological factor dan preceptions and expectations.
Image objek wisata timbul relatifitasnya disebabkan oleh cara penafsirannya yang subjektif antara seorang dengan yang lainnya dan sangat tergantung dengan perbandingan yang akan digunakan. Citra destinasi adalah penggerak utama yang mengacu pada persepsi umum wisatawan, dan dapat mempengaruhi kepuasan dan perilaku dimasa yang akan datang. Semakin tinggi pengaruh presepsi positif yang diberikan, maka wisatawan akan merasa puas dan semakin besar juga kemungkinan wisatawan untuk melakukan niat kunjung ulang. Pendapat diatas dipertegas dengan penelitian yang dilakukan oleh Pujiastuti et al., (2017) membuktikan bahwa destination image memiliki pengaruh positif terhadap behavior intention melalui tourist satisfaction. Berdasarkan uraian diatas menjadi sarana acuan peneliti untuk mengembangkan hipotesis sebagai berikut:

$H_{6}$ : Destination image berpengaruh signifikan terhadap post visit behavior intention melalui tourist satisfaction.

\section{g. Pengaruh Tourist Attraction terhadap Post Visit Behavior Intention melalui Tourist Satisfaction}

Kepuasan merupakan hal positif dalam sebuah psikologis seseorang, karena dengan adanya kepuasan berarti bahwa produsen atau pengelola sudah dapat memenuhi kebutuhan, keinginan dan harapan konsumen atas suatu produk atau jasa, sehingga berdampak pada perilaku konsumen terhadap perilaku berikutnya. Daya tarik wisata segala sesuatu yang menjadi daya tarik bagi orang untuk mengunjungi daerah wisata tertentu mempunyai ke khususan dan berbeda dari objek yang lain (Yoeti (1997) dalam Suwena dan 
Widyatmaja 2017:155). Salah satu faktor pendorong post visit behavior intention menurut Khan, dkk (1993) dalam Utama (2017:114) adalah destination attribute and type facilities, sedangkan beberapa faktor kepuasan wisatawan menurut Irawan (2002:37) adalah kualitas produk, service quality, dan kemudahan. Daya tarik alam objek wisata jika semakin dikembangkan dengan beberapa inovasi-inovasi baru maka dapat berpengaruh pada kepuasan konsumen untuk mengunjungi ulang objek wisata. Pendapat diatas dipertegas dengan penelitian yang dilakukan oleh Hsieh (2012) membuktikan bahwa tourist attraction berpengaruh positif terhadap post visit behaviour intention. Berdasarkan uraian diatas menjadi sarana acuan peneliti untuk mengembangkan hipotesis sebagai berikut:

$\mathrm{H}_{7} \quad$ : Tourist attraction berpengaruh signifikan terhadap post visit behavior intention melalui tourist satisfaction.

Adapun model hipotesis sebagai berikut:

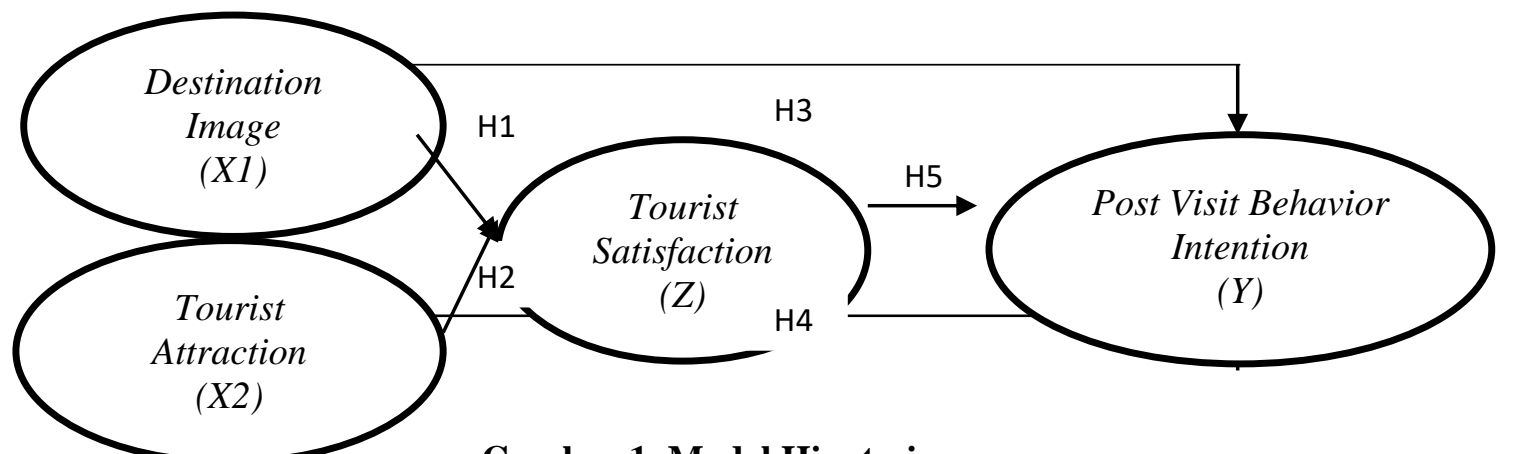

Keterangan:

Gambar 1. Model Hipotesis

$$
\begin{aligned}
& \mathrm{H}_{6}=\mathrm{X} 1 \rightarrow \mathrm{Z} \rightarrow \mathrm{Y} \\
& \mathrm{H}_{7}=\mathrm{X} 2 \rightarrow \mathrm{Z} \rightarrow \mathrm{Y}
\end{aligned}
$$

\section{Metodologi}

Tipe penelitian yang digunakan dalam penelitian ini adalah tipe penelitian explanatory yang berupaya untuk menjelaskan ada tidaknya pengaruh suatu variabel dengan variabel lainnya. Sampel dalam penelitian ini adalah sebagian dari wisatawan yang berkunjung ke Kebun Buah Mangunan dengan karakteristik usia 18-38 tahun karena usia tersebut merupakan generasi milenial, dan berdasarkan hasil survei profil wisatawan, data menunjukan bahwa generasi tersebut yang menduduki peringkat pertama. Ukuran sampel yang didasarkan atas pertimbangan teknik analisis yang dipergunakan dalam penelitian Matchin dan Campbel (1989). Adapun jumlah sampel yang dipergunakan sebanyak 115 orang. Metode yang digunakan adalah systematic random sampling (pada populasi yang tak terbatas). Alat ukur yang digunakan dalam kuesioner adalah menggunakan Skala Likert. Sesuai dengan model yang dikembangkan pada penelitian ini, maka alat analisis data yang digunakan adalah SEM yang dioperasikan dengan menggunakan aplikasi AMOS. Uji Hipotesis menggunakan uji $\mathrm{t}$ dengan taraf signifikan $5 \%$. 


\section{Hasil Penelitian}

Berdasarkan hasil pengujian menggunakan SEM AMOS sebagai berikut:

Tabel 1. Uji Hipotesis

\begin{tabular}{|c|c|c|c|c|c|c|c|}
\hline & & & Estimate & S.E. & C.R. & P & Kesimpulan \\
\hline TS & $<---$ & DI & 0,356 & 0,106 & 3,350 & 0,000 & Diterima \\
\hline TS & $<---$ & TA & 0,234 & 0,089 & 2,626 & 0,009 & Diterima \\
\hline PVB & $<---$ & DI & 0,318 & 0,108 & 2,953 & 0,003 & Diterima \\
\hline PVB & $<---$ & TA & 0,195 & 0,088 & 2,214 & 0,027 & Diterima \\
\hline PVB & $<---$ & TS & 0,438 & 0,107 & 4,102 & 0,000 & Diterima \\
\hline
\end{tabular}

*Ket: DI (Destination Image)

TA(Tourist Attraction)

TS(Tourist Satisfaction)

PVA (Post Visit Behavior Intention)

a. Pengujian Hipotesis1: Pengaruh destination image terhadap tourist satisfaction

Hasil analisis dengan AMOS untuk pengujian pengaruh destination image terhadap tourist satisfaction menunjukkan nilai probabilitas sebesar 0,000 . Nilai probabilitas sebesar 0,000 berada kurang dari signifikansi probabilitas 0,05 . Hal ini terbukti bahwa hipotesis kesatu dalam penelitian ini dapat diterima. Hal ini berarti bahwa destination image berpengaruh signifikan terhadap tourist satisfaction. Nilai critical ratio (CR) sebesar 3,350, hal ini dapat diartikan citra destinasi mempunyai pengaruh terhadap kepuasan wisatawan sebesar 3,350 Adanya pengaruh positif antara citra destinasi terhadap kepuasan wisatawan menunjukkan semakin tinggi dan semakin baik citra destinasi yang dipahami responden akan mudah menciptakan kepuasan.

b. Pengujian Hipotesis2: Pengaruh tourist attraction terhadap tourist satisfaction
Hasil analisis dengan AMOS untuk pengujian pengaruh tourist attraction terhadap tourist satisfaction menunjukkan nilai probabilitas sebesar 0,000 . Nilai probabilitas sebesar 0,000 berada kurang dari signifikansi probabilitas 0,05 . Hal ini terbukti bahwa hipotesis kesatu dalam penelitian ini dapat diterima. Hal ini berarti bahwa tourist attraction berpengaruh signifikan terhadap tourist satisfaction. Nilai critical ratio $(\mathrm{CR})$ sebesar 2,626, hal ini dapat diartikan tourist attraction mempunyai pengaruh terhadap kepuasan wisatawan sebesar 2,626 Adanya pengaruh positif antara tourist attraction terhadap kepuasan wisatawan menunjukkan semakin tinggi dan semakin baik tourist attraction yang diterima responden maka akan menimbulkan kepuasan.

c. Pengujian Hipotesis3: Pengaruh destination image terhadap post visit behavior intention

Hasil analisis dengan AMOS untuk pengujian pengaruh destination image terhadap post 
visit behavior intention menunjukkan nilai probabilitas sebesar 0,000. Nilai probabilitas sebesar 0,000 berada kurang dari signifikansi probabilitas 0,05 . Hal ini terbukti bahwa hipotesis kesatu dalam penelitian ini dapat diterima. Hal ini berarti bahwa destination image berpengaruh signifikan terhadap post visit behavior intention. Nilai critical ratio (CR) sebesar 2,953, hal ini dapat diartikan citra destinasi mempunyai pengaruh terhadap post visit behavior intention sebesar 2,953. Adanya pengaruh positif antara citra destinasi terhadap post visit behavior intention menunjukkan semakin tinggi dan semakin baik citra destinasi yang dipahami responden akan meningkatkan keingginan membeli ulang di masa yang akan datang.

d. Pengujian Hipotesis4: Pengaruh tourist attraction terhadap post visit behavior intention

Hasil analisis dengan AMOS untuk pengujian pengaruh tourist attraction terhadap post visit behavior intention menunjukkan nilai probabilitas sebesar 0,000. Nilai probabilitas sebesar 0,000 berada kurang dari signifikansi probabilitas 0,05 . Hal ini terbukti bahwa hipotesis kesatu dalam penelitian ini dapat diterima. Hal ini berarti bahwa tourist attraction berpengaruh signifikan terhadap post visit behavior intention. Nilai critical ratio (CR) sebesar 2,214, hal ini dapat diartikan tourist attraction mempunyai pengaruh terhadap post visit behavior intention sebesar 2,214. Adanya pengaruh positif antara tourist attraction terhadap post visit behavior intention menunjukkan semakin tinggi dan semakin baik tourist attraction yang diterima responden maka akan menimbulkan keinginan membeli ulang di masa yang akan datang.

e. Pengujian Hipotesis5 : Pengaruh tourist satisfaction terhadap post visit behavior intention

Hasil analisis dengan AMOS untuk pengujian pengaruh tourist satisfaction terhadap post visit behavior intention menunjukkan nilai probabilitas sebesar 0,000. Nilai probabilitas sebesar 0,000 berada kurang dari signifikansi probabilitas 0,05 . Hal ini terbukti bahwa hipotesis kesatu dalam penelitian ini dapat diterima. Hal ini berarti bahwa tourist satisfaction berpengaruh signifikan terhadap post visit behavior intention. Nilai critical ratio (CR) sebesar 4,102, hal ini dapat diartikan tourist satisfaction mempunyai pengaruh terhadap post visit behavior intention sebesar 4,102. Adanya pengaruh positif antara tourist attraction terhadap post visit behavior intention menunjukkan semakin tinggi dan semakin baik tourist satisfaction yang diterima responden maka akan menimbulkan keinginan membeli ulang di masa yang akan datang.

Berdasarkan tabel diatas, maka selanjutnya untuk mengetahui pengaruh tidak langsung dari variabel mediasi antara pengaruh destination image dan tourist attraction terhadap post visit behavior intention melalui tourist satisfaction sebagai variabel mediasi yaitu sebagai berikut: 


\section{Pengaruh Langsung (Direct Effects)}

Tabel 2. Standardized Direct Effects

\begin{tabular}{|l|r|r|r|r|}
\hline & TA & DI & TS & PVB \\
\hline TS &, 258 &, 337 &, 000 &, 000 \\
\hline PVB &, 196 &, 275 &, 400 &, 000 \\
\hline
\end{tabular}

(Sumber : Standardized Direct Effects-Default model AMOS 22, 2019)

a. Pengaruh destination image terhadap post visit behavior intention adalah 0,275 .

b. Pengaruh tourist attraction terhadap post visit behavior intention adalah 0,196 .

2. Pengaruh Tidak Langsung (Indirect Effects)

Tabel 3. Standardized Direct Effects

\begin{tabular}{|l|r|r|r|r|}
\hline & TA & DI & TS & PVB \\
\hline TS &, 000 &, 000 &, 000 &, 000 \\
\hline PVB &, 103 &, 135 &, 000 &, 000 \\
\hline
\end{tabular}

(Sumber : Standardized Indirect Effects-Default model AMOS 22, 2019)

a. Pengaruh destination image terhadap post visit behavior intention melalui tourist satisfaction adalah 0,135 .

b. Pengaruh tourist attraction terhadap post visit behavior intention melalui tourist satisfaction adalah 0,103.

3. Pengaruh Total (Total Effects)

Tabel 4. Standardized Total Effects

\begin{tabular}{|l|r|r|r|r|}
\hline & TA & DI & TS & PVB \\
\hline TS &, 258 &, 337 &, 000 &, 000 \\
\hline PVB &, 299 &, 410 &, 400 &, 000 \\
\hline
\end{tabular}

(Sumber : Total Effects-Default model AMOS 22, 2019)

a. Standardized Total Effects pada variabel destination image, post visit behavior intention dan tourist satisfaction adalah : $0,275+0,135=$ 0,410

b. Standardized Total Effects pada variabel tourist attraction, post visit behavior intention dan tourist satisfaction adalah : 0,196 +0,103 =0,299

f. Pengujian Hipotesis 6 : Pengaruh destination image terhadap post visit behaviour intention melalui tourist satisfaction

Hasil pengujian analisis menunjukkan bahwa destination image berpengaruh terhadap post visit behaviour intention dengan koefisien standardized direct effect sebesar
0,275. Pengaruh destination image terhadap loyalitas destinasi melalui kepuasan wisatawan dengan koefisien standarized indirect effects sebesar 0,135 , sehingga nilai standarized total effect sebesar 0,410. Nilai standarized indirect effects lebih besar dari nilai standardized direct effect sehingga dapat dikatakan pengaruh destination image terhadap post visit behaviour 
intention akan lebih besar jika melalui kepuasan wisatawan. Hal ini berarti meningkatnya kepuasan wisatawan yang disebabkan oleh semakin baik dan semakin positif destination image maka dapat meningkatkan post visit behaviour intention terhadap destinasi.

g. Pengujian Hipotesis 7: Pengaruh tourist attraction terhadap post visit behavior intention melalui tourist satisfaction.

Hasil pengujian analisis menunjukkan bahwa tourist attraction berpengaruh terhadap post visit behavior intention dengan koefisien standardized direct effect sebesar 0,196. Pengaruh tourist attraction terhadap post visit behavior intention melalui kepuasan wisatawan dengan koefisien standarized indirect effects sebesar 0,103, sehingga nilai standarized total effect sebesar 0,299. Nilai standarized indirect effects lebih besar dari nilai standardized direct effect sehingga dapat dikatakan pengaruh tourist attraction terhadap post visit behavior intention akan lebih besar jika melalui kepuasan wisatawan. Hal ini berarti meningkatnya kepuasan wisatawan yang disebabkan oleh semakin baiknya tourist attraction untuk berkunjung maka dapat meningkatkan post visit behavior intention.

\section{Pembahasan}

\section{Pengaruh Destination Image terhadap Tourist Satisfaction}

Hasil penelitian ini menunjukan bahwa destination image berpengaruh signifikan terhadap tourist satisfaction. Nilai koefisien bertanda positif mengandung arti bahwa semakin positif citra destinasi maka akan dapat meningkatkan tourist satisfaction. Hasil penelitian ini adalah destination image berpengaruh positif dan signifikan terhadap tourist satisfaction. Hasil penelitian ini secara empirik mendukung penelitian sebelumnya yang dilakukan oleh Pujiastuti et al., (2017), Manhas dan Ramjit (2013), Tang (2014), Khan et al., (2013), dan Naidoo et al.,(2011) membuktikan bahwa destination image memiliki pengaruh positif terhadap tourist satisfaction. Hasil penelitian ini juga didukung oleh konsep Parenteau 1995 dalam Utama (2017:221) yang menyatakan bahwa destination image merupakan prasangka positif atau negatif yang dimiliki oleh seorang tentang sebuah produk atau destinasi. Salah satu faktor pembentuk kepuasan wisatawan menurut Irawan (2002:37) adalah emotional factors, yaitu wisatawan merasa yakin dengan objek wisata yang mereka kunjungi, persepsi yang baik akan muncul jika realita dan ekspeksasi tentang objek wisata dinilai sesuai oleh wisatawan. Prasangka positif tersebut akan berdampak pada kepuasan wisatawan saat berkunjung. Persepsi tersebut muncul berdasarkan kesan yang didapat oleh wisatawan saat berkunjung. Persepsi yang baik akan muncul jika realita dan ekspektasi tentang objek wisata dinilai sesuai oleh wisatawan. Persepsi positif tersebut akan berdampak pada kepuasan wisatawan saat berkunjung. Hasil Penelitian ini menunjukan bahwa variabel destination image cukup penting dalam rangka meningkatkan tourist satisfaction, semakin baik citra destinasi wisata maka akan dapat meningkatkan tingkat kepuasan wisatawan. Oleh sebab itu, pengelola harus bekerja keras untuk membangun, memperkenalkan, dan mempertahankan image positif Kebun Buah Mangunan agar para wisatawan merasa selalu puas. 


\section{Pengaruh Tourist Attraction terhadap Tourist Satisfaction}

Hasil penelitian ini telah membuktikan bahwa tourist attraction berpengaruh signifikan terhadap tourist satisfaction. Nilai koefisien bertanda positif mengandung arti bahwa semakin positif daya tarik wisata yang ada maka akan meningkatkan tourist satisfaction. Hasil penelitian ini adalah tourist attraction berpengaruh positif dan signifikan terhadap tourist satisfaction. Hasil penelitian ini secara empirik mendukung penelitian sebelumnya yang dilakukan oleh Naidoo et al., (2012), dan juga Manhas dan Ramjit (2013) membuktikan bahwa tourist attraction memiliki pengaruh positif terhadap tourist satisfaction. Hasil penelitian ini juga didukung oleh konsep Pandit (2003) dalam Utama (2017:142) yang menyatakan bahwa daya tarik wisata adalah segala sesuatu yang menarik dan mempunyai nilai untuk dikunjungi dan dilihat. Daya tarik wisata merupakan salah satu pemicu kepuasan wisatawan dan juga merupakan pendorong agar wisatawan rela berkunjung ke suatu objek wisata. Beberapa faktor kepuasan wisatawan menurut Irawan (2002:37) adalah kualitas produk, service quality, dan kemudahan. Wisatawan merasa puas bila hasil evaluasi menunjukan bahwa objek wisata yang dikunjungi mempunyai fasilitas yang baik, seperti fasilitas umum yang ada. Wisatawan akan merasa puas apabila mereka mendapatkan pelayanan yang baik dari pengelola objek wisata atau dalam arti lain yaitu sesuai dengan harapkan wisatawan. Wisatawan merasa puas karena lokasi objek wisata yang mudah dijangkau. Maka dari itu, daya tarik wisata merupakan hal yang penting dalam kepuasan wisatawan, sebab daya tarik merupakan pembeda dan menjadi suatu yang dapat ditawarkan untuk memenuhi keinginan Hasil Penelitian ini menunjukkan bahwa variabel tourist attraction cukup penting dalam rangka meningkatkan tourist satisfaction, sebab daya tarik merupakan pembeda unik yang dapat ditawarkan untuk memenuhi keinginan wisatawan sehingga menjadikannya puas maka akan dapat meningkatkan tingkat kepuasan wisatawan. Oleh sebab itu, pengelola harus bekerja keras untuk mencari konsep atau ide baru yang unik untuk dijadikan daya tarik wisata, sehingga wisatawan yang berkunjung dapat puas menikmati daya tarik wisata tersebut.

\section{Pengaruh Destination Image terhadap Post Visit Behavior Intention}

Hasil penelitian ini telah membuktikan destination image berpengaruh signifikan terhadap post visit behavior intention. Nilai koefisien bertanda positif mengandung arti bahwa semakin positif image suatu objek wisata maka akan meningkatkan kemungkinan wisatawan dalam post visit behavior intention. Hasil penelitian ini adalah destination image berpengaruh positif dan signifikan terhadap post visit behavior intention. Hasil penelitian ini secara empirik mendukung penelitian sebelumnya yang dilakukan oleh Moon et al., (2013), Pujiastuti et al., (2017), Tang (2013), Hsieh (2012) membuktikan bahwa destination image memiliki pengaruh positif terhadap post visit behavior intention. Hasil penelitian ini juga didukung oleh konsep Barnest (2003:315) menyatakan bahwa pengalaman aktif, menciptakan nilai yang sangat besar merupakan komponen dari terbentuknya citra destinasi. Citra destinasi adalah penggerak utama yang mengacu pada persepsi umum wisatawan, dan dapat 
mempengaruhi perilaku di masa yang akan datang. Hasil Penelitian ini menunjukkan bahwa variabel destination image cukup penting dalam rangka meningkatkan post visit behavior intention, sebab citra tempat wisata dapat menjadi salah satu pertimbangan wisatawan untuk melakukan kunjungan ulang. Oleh sebab itu, pengelola bisa menjadikan keunikan objek menjadi ikon agar mudah dikenal, dan karena sudah dikenal itulah dapat memicu wisatawan melakukan post visit behavior.

\section{Pengaruh Tourist Attraction terhadap Post Visit Behavior Intention}

Hasil penelitian ini telah membuktikan tourist attraction berpengaruh signifikan terhadap post visit behavior intention. Nilai koefisien bertanda positif mengandung arti bahwa semakin tinggi daya tarik suatu objek wisata maka akan meningkatkan kemungkinan wisatawan dalam post visit behavior intention. Hasil penelitian ini adalah tourist attraction berpengaruh positif dan signifikan terhadap post visit behavior intention. Hasil penelitian ini secara empirik mendukung penelitian sebelumnya yang dilakukan oleh Hsieh (2012) membuktikan bahwa tourist attraction memiliki pengaruh positif terhadap post visit behavior intention. Hasil penelitian ini juga didukung oleh konsep Yoeti (1997) dalam Suwena dan Widyatmaja (2017:155) menyatakan bahwa daya tarik wisata merupakan segala sesuatu yang menjadi daya tarik bagi wisatawan untuk mengunjungi daerah wisata tertentu mempunyai kekhususan dan berbeda dari objek yang lain. Penelitian ini menunjukkan bahwa variabel tourist attraction cukup penting dalam rangka meningkatkan post visit behavior intention, sebab citra tempat wisata dapat menjadi salah satu pertimbangan wisatawan untuk melakukan kunjungan ulang. Oleh sebab itu, pengelola bisa mengembangkan trend saat ini untuk menjadi daya tarik objek wisata, agar para wisatawan yang sudah berkunjung tidak akan bosan untuk kembali lagi.

\section{Pengaruh Tourist Satisfaction terhadap Post Visit Behavior Intention}

Hasil penelitian ini telah membuktikan tourist satisfaction berpengaruh signifikan terhadap post visit behavior intention. Nilai koefisien bertanda positif mengandung arti bahwa semakin tinggi tingkat kepuasan wisatawan maka akan meningkatkan kemungkinan wisatawan dalam post visit behavior intention. Hasil penelitian ini adalah tourist satisfaction berpengaruh positif dan signifikan terhadap post visit behavior intention. Hasil penelitian ini secara empirik mendukung penelitian sebelumnya yang dilakukan oleh Manhas dan Ramjit (2013), Pujiastuti et al. (2017) dan Tang (2013) membuktikan bahwa tourist satisfaction memiliki pengaruh positif terhadap post visit behavior intention. Hasil penelitian ini juga didukung oleh konsep Suwena dan Widyatmaja (2017:75) menyatakan bahwa kepuasan wisatawan adalah perbandingan antara apa yang diharapkan dengan tingkat kinerja yang dirasakan oleh wisatawan. Kepuasan merupakan hal positif dalam sebuah psikologis seseorang, karena dengan adanya kepuasan berarti bahwa pengelola objek wisata sudah dapat memenuhi kebutuhan, keinginan dan harapan wisatawan atas suatu jasa, sehingga berdampak pada perilaku konsumen terhadap perilaku berikutnya. Penelitian ini menunjukkan bahwa variabel tourist satisfaction 
cukup penting dalam rangka meningkatkan post visit behavior intention, sebab tingkat kepuasan yang tinggi dapat memicu wisatawan untuk melakukan kunjungan ulang. Oleh sebab itu, pengelola diharapkan mampu mengetahui tingkat kepuasan wisatawan saat berkunjung, bisa dengan cara penyediaan kotak penilaian atau isi kuesioner untuk mengetahui hal apa saja yang dapat membuat wisatawan puas, jika kepuasan itu tercapai, maka wisatawan tidak akan ragu untuk melakukan rekomendasi ke orang lain, atau membuat review tentang objek wisata Kebun Buah Mangunan bahkan berkunjung kembali.

\section{Pengaruh Destination Image terhadap Post Visit Behavior Intention melalui Tourist Satisfaction}

Hasil penelitian ini telah membuktikan destination image berpengaruh secara tidak langsung terhadap post visit behavior intention melalui tourist satisfaction. Nilai koefisien bertanda positif mengandung arti bahwa semakin positif image suatu objek wisata maka akan meningkatkan kepuasan dan post visit behavior intention. Hasil penelitian ini adalah destination image berpengaruh secara tidak langsung terhadap post visit behavior intention melalui tourist satisfaction. Hasil penelitian ini secara empirik mendukung penelitian sebelumnya yang dilakukan oleh Pujiastuti et al., (2017), membuktikan bahwa destination image memiliki pengaruh positif terhadap post visit behavior intention melalui tourist satisfaction. Hasil penelitian ini juga didukung oleh konsep Barnest (2003:315) menyatakan bahwa pengalaman aktif, menciptakan nilai yang sangat besar merupakan komponen dari terbentuknya citra destinasi. Image merupakan salah satu komponen pembentuk faktor kepuasan wisatawan yaitu emotional factor yang dapat mempengaruhi kepuasan wisatawan sehingga berdampak pada post visit behavior intention. Hasil Penelitian ini menunjukan bahwa variabel tourist satisfaction cukup penting dalam rangka meningkatkan wisatawan untuk melakukan post visit behavior intention. Oleh sebab itu, pengelola harus bisa mencari cara agar wisatawan selalu puas saat berkunjung ke tempat wisata, sebab meningkatkan nilai kepuasan adalah pemicu wisatawan dalam melakukan post visit behavior intention.

\section{Pengaruh Tourist Attraction terhadap Post Visit Behavior Intention melalui Tourist Satisfaction}

Hasil penelitian ini telah membuktikan tourist attraction berpengaruh secara tidak langsung terhadap post visit behavior intention melalui tourist satisfaction. Nilai koefisien bertanda positif mengandung arti bahwa semakin tinggi daya tarik suatu objek wisata maka dapat meningkatkan kepuasan dan post visit behavior intention. Hasil penelitian ini adalah tourist attraction berpengaruh secara tidak langsung terhadap post visit behavior intention melalui tourist satisfaction. Hasil penelitian ini secara empirik mendukung penelitian sebelumnya yang dilakukan oleh Hsieh (2012) dan Mashas dan Ramjit (2013), membuktikan bahwa tourist attraction memiliki pengaruh positif terhadap post visit behavior intention melalui tourist satisfaction. Penelitian ini juga didukung oleh konsep Yoeti (1997) dalam Suwena dan Widyatmaja (2017:155) menyatakan bahwa daya tarik wisata merupakan segala sesuatu yang menjadi daya tarik bagi wisatawan untuk mengunjungi daerah 
wisata tertentu mempunyai ke khususan dan berbeda dari objek yang lain. Daya tarik wisata berpengaruh terhadap tingkat kepuasan wisatawan yang berdampak pada post visit behavior intention. Penelitian ini menunjukkan bahwa variabel tourist satisfaction cukup penting dalam rangka meningkatkan post visit behavior intention, sebab tingginya tingkat kepuasan wisatawan yang disebabkan oleh daya tarik wisata maka berdampak pada post visit behavior intention. Oleh sebab itu, pengelola harus bisa mengembangkan inovasiinovasi daya tarik wisata sesuai dengan trend yang ada, hal tersebut dapat memicu wisatawan melakukan post visit behavior intention dikarenakan wisatawan merasa puas saat berkunjung ke tempat wisata.

\section{Kesimpulan}

Berdasarkan hasil analisis dan pembahasan, maka dapat ditarik kesimpulan bahwa:

1. Destination image berpengaruh signifikan terhadap tourist satisfaction. Hal ini berarti image positif objek wisata Kebun Buah Mangunan dapat menciptakan kepuasan pada wisatawan.

2. Tourist attraction berpengaruh signifikan terhadap tourist satisfaction. Hal ini berarti daya tarik wisata berupa fasilitas, pengalaman dan aktivitas yang didapatkan wisatawan di Kebun Buah Mangunan dapat mendorong kepuasan pada wisatawan.

3. Destination image berpengaruh signifikan terhadap post visit behavior intention. Hal ini berarti image positif objek wisata Kebun Buah Mangunan dapat mendorong wisatawan untuk kembali datang berwisata.
4. Tourist attraction berpengaruh signifikan terhadap post visit behavior intention. Hal ini berarti daya tarik wisata berupa fasilitas, pengalaman dan aktivitas yang didapatkan wisatawan di Kebun Buah Mangunan dapat mendorong wisatawan untuk kembali datang berwisata.

5. Tourist satisfaction berpengaruh signifikan terhadap post visit behavior intention. Hal ini berarti kepuasan yang didapatkan wisatawan di Kebun Buah Mangunan dapat mendorong wisatawan untuk kembali datang berwisata.

6. Destination image berpengaruh secara tidak langsung terhadap post visit behavior intention melalui tourist satisfaction. Hal ini berarti adanya image positif pada objek wisata Kebun Buah Mangunan dapat memberikan rasa puas pada wisatawan. Kepuasan wisatawan dapat mempengaruhi atau mendorong wisatawan untuk kembali datang berwisata.

7. Tourist attraction berpengaruh secara tidak langsung terhadap post visit behavior intention melalui tourist satisfaction. Hal ini berarti adanya daya tarik wisata berupa fasilitas, pengalaman dan aktivitas yang didapatkan wisatawan dapat memberian rasa puas pada wisatawan. Kepuasan wisatawan dapat mempengaruhi atau mendorong wisatawan untuk kembali datang berwisata.

\section{Saran}

Saran dari penulis untuk peneliti selanjutnya diharapkan dapat meneliti dengan jenis variabel-variabel yang berbeda diluar variabel yang sudah penulis teliti agar memperoleh hasil yang lebih variatif dan mengetahui 
variabel-variabel lain yang mungkin dapat mempengaruhi kepuasan wisatawan dan berdampak pada minat mengunjungi kembali. Peneliti selanjutnya juga dapat meneliti objek wisata yang lain, dengan kriteria objek wisata yang berbeda, yang mana hasil penelitian dapat memberikan keragaman hasil dari penelitian sebelumnya dan menambah kaidah bagi keilmuan.

\section{Daftar Pustaka}

Aktivitas wisatawan. (https://wisatapedi.com/kebunbuah-mangunan-imogiri-dlingobantul-jogja-lokasi-penginapanrute/. Diakses 27 Januari 2019 pukul 20:50).

Barnest, G. James. 2003. Secrets of Customer Relationship Management. Yogyakarta :ANDI.

Daryanto, 2011. Sari Kuliah Manajemen Pemasaran, Bandung: PT. Sarana Tutorial Nurani Sejahtera.

Generasi Milenial. 2017. https://beritagar.id/artikel/gayahidup/milenial-adalah-raja-piknikdi-indonesia. Diakses pada tanggal 25 November 2018, pukul 15:38 WIB.

Gozali, Imam. 2013. Konsep dan Aplikasi dengan Platform AMOS 21.0. Semarang : Badan Penerbit Universitas Diponegoro.

Hsieh. 2012. A Study of Tourists on Attraction, Service Quality, Perceived Value and Behavioral Intention in the Penghu Ocean Firework Festival. The Journal of International Management Studies. Vol. 7, No. 2, 79-92.

Irawan, Handi, 2002. 10 Prinsip Kepuasan Pelanggan, Jakarta: PT Elex Media Komputindo.
Ismayanti, 2010. Pengantar Pariwisata. Jakarta: Grasindo.

Letak koordinat Kebun Buah Mangunan

(http://mangunan.bantulkab.go.id/i ndex.php/first/ artikel /33. Diakses 27 Januari 2019 pukul 20:00).

Khan, Haque, dan Rahman, 2013. What Makes Tourist Satisfied? An Empirical Study on Malaysian Islamic Tourist Destination. Middle-East Journal of Scientific Research, Vol. 14, No. 12, 16311637.

Kotler, Philip dan Kevin Lane Keller. 2009. Manajemen Pemasaran, Edisi 13, Jilid 1. Jakarta :PT Gelora Aksara Pratama, Erlangga.

Kotler, Philip dan Gary Amstrong, 2008. Prinsip-Prinsip Pemasaran, Edisi 12, jilid 1. Jakarta: Erlangga

Manhas dan Ramjit, 2013. Customer Experience and Its Relative Influence on Satisfaction and Behavioural Intention in Hospitality and Tourism Industry. South Asian Journal of Tourism and Heritage, 54-68.

Marcomm,2018. Millennials. Jakarta : Fantasious x Loveable.

Machin, D., and Campbell, M.J., (1989), Statistical Tables for The Design of Clinical Trials, London: Blackwell Scientific Publication. p. 89-93

Moon, Ko, Connaughton, dan Lee, 2013. A Mediating Role of Destination Image in the Relationship between Event Quality, Perceived Value, and Behavioral Intention, Journal sport and Tourism. Vol. 49-66.

Mowen dan Minor, 2002. Perilaku Konsumen. Jakarta: Erlangga

Munhurrun, Seebaluck, dan Naidoo. 2014. Examining The Structural Relationships of Destination 
Image, Perceived Value, Tourist Satisfaction And Loyalty: Case of Mauritius. International Conference on Strategic Innovative Marketing. 252 - 259

Naidoo, Munhurrun, dan Segoolam 2011 The Assessement of Visitor Satisfaction With Nature-Based Tourism Attractions. International Journal of Management And Marketing Research. Vol. 4, No.1, 87-98.

Oliver, R. L. Cognitive, Affective, and Attribute Bases of the Satisfaction Response. Journal of Consumer Research, 20, pp. 418-430, 1993

Oliver, R. L. Satisfaction: A Behavioural Perspective on the Consumer, New York: McGraw Hill, 1997

Pitana, I Gede dan Surya Diarta, I Ketut. 2009. Pengantar Ilmu Pariwisata. Yogyakarta: Andi

Profile Kebun Buah Mangunan. 2016. (http://www.pikiranrakyat.com/wisata/2016/01/08/356 276/kebun-buah-mangunan-kianterkenal,8 Januari 2016 (Diakses pada tanggal 11 September 2018, pukul 19:10 WIB).

Profil Penduduk yang Berwisata. 2017. (http://debcornels.blogspot.com/20 17/11/generasi-millennial_29.html. Diakses pada tanggal 25 November 2018, pukul 15:33 WIB).

Pujiastuti, Nimran, Suharyono, dan Kusumawati, 2017. Study On Destination Image Satisfaction Trust And Behavioral Intention: a Study in the tourist village in Sleman, Yogyakarta. International Journal of Administrative Science, 148-159.

Pujiastuti, Nimran, Suharyono dan Kusumawati. 2017. The Antecedents Behavioral Intention
Regarding Rural Tourism Destination. Asia Pacific Journal of Tourism Research. Vol. 22, No. 11, 1169-1181.

Rekapitulasi Wisatawan Pariwisata Daerah Istimewa Yogyakarta. 2012-2016

(https://visitingjogja.com/ .Diakses pada tanggal 11 September 2018, pukul 18:45 WIB)

Review Wisatawan Kebun Buah Mangunan. 2016-2017. (https://www.tripadvisor.co.id/Attr action_Review-g294230d8062041-Reviews-or40Fruit_Garden_Mangunan_Yogyak arta-Yogyakarta Java.html

Diakses pada tanggal 11
September 2018, pukul 19:08 WIB).

Riduwan, 2010. Dasar-Dasar Statistika. Bandung: Alfabeta.

Schiffman dan Kanuk, 2007. Perilaku Konsumen. Jakarta: Gramedia.

Sugiyono, 2014. Metode Penelitian Bisnis. Bandung: Alfabeta.

Suwena IK. dan Widyaatmaja, 2017. Pengetahuan Dasar Ilmu Pariwisata. Bali: Pustaka Larasan.

Tang, 2014 Travel Motivation, Destination Image and Visitor Satisfaction of International Tourists After the 2008 Wenchuan Earthquake: A Structural Modelling Approach, Asia Pasific Journal of Tourism Research. Vol. 19, No. 11, 1260-1277.

Tjiptono, Fandy, 2014. Pemasaran Jasa Prinsip, Penerapan, dan Penelitian. Yogyakarta: Andi Offset.

Undang- Undang Republik Indonesia Nomor 10 Tahun 2009 tentang Pariwisata.

Utama, I Gusti Bagus Rai. 2017. Pemasaran Pariwisata. Yogyakarta. Penerbit: Andi. 
